\title{
Anti-stress effects of human placenta extract: possible involvement of the oxidative stress system in rats
}

Hyun-Jung Park ${ }^{1,5}$, Hyun Soo Shim', Sunyoung Lee ${ }^{1}$, Dae Hyun Hahm ${ }^{1,4}$, Hyejung Lee ${ }^{1}$, Chang Taek Oh², Hae Jung $\mathrm{Han}^{2}$, Hyi Jeong $\mathrm{Ji}^{3}$ and Insop Shim ${ }^{1,4^{*}}$

\begin{abstract}
Background: Human placenta hydrolysate (hPH) has been utilized to improve menopausal, fatigue, liver function. Its high concentration of bioactive substances is known to produce including antioxidant, anti-inflammatory and anti-nociceptive activities. However, its mechanisms of stress-induced depression remain unknown.

Methods: The present study examined the effect of hPH on stress-induced depressive behaviors and biochemical parameters in rats. $\mathrm{hPH}(0.02 \mathrm{ml}, 0.2 \mathrm{ml}$ or $1 \mathrm{ml} /$ rat $)$ was injected intravenously 30 min before the daily stress session in male Sprague-Dawley rats exposed to repeated immobilization stress (4 h/day for 7 days). The depressive-like behaviors of all groups were measured by elevated plus maze (EPM) and forced swimming test (FST). After the behavior tests, brain samples of all groups were collected for the analysis of glutathione peroxidase (GPX) and nicotinamide adenine dinucleotide phosphate-diaphorase (NADPH-d) staining.
\end{abstract}

Results: Treatment with hPH produced a significant decrease of immobility time in the FST compared to the controls. Additionally, hPH treatment elicited a slightly decreasing trend in anxiety behavior on the EPM.

Furthermore, hPH increased the level of GPx protein in the hippocampus, and decreased the expression of NADPH$\mathrm{d}$ in the paraventricular nucleus (PVN).

Conclusion: This study demonstrated that hPH has anti-stress effects via the regulation of nitric oxide (NO) synthase and antioxidant activity in the brain. These results suggest that $\mathrm{hPH}$ may be useful in the treatment of stress-related diseases such as chronic fatigue syndrome.

Keywords: Fatigue, Forced swimming test, Glutathione peroxidase (GPx), Human placenta hydrolysate (hPH), Nicotinamide adenine dinucleotide phosphate-diaphorase (NADPH-d), Immobilization stress

\section{Background}

Stress is a common and unavoidable phenomenon in life, and excess stress influences mental and physical health. Repeated immobilization stress are activated the hypothalamic-pituitary adrenal (HPA) axis also that results in the release of stress hormone such as catecholamines and catecholamines [1]. High concentration of glucocorticoids show both short and long-term negative changes on emotional and physiological effects [2]. At

\footnotetext{
* Correspondence: ishim@khu.ac.kr

'Department of Science in Korean Medicine, Graduate School, College of Korean Medicine, Kyung Hee University, Seoul 02447, South Korea

${ }^{4}$ Department of Physiology, College of Medicine, Kyung Hee University, Seoul, South Korea

Full list of author information is available at the end of the article
}

the behavioral response, repeated stress has been increased depressive behaviors such as anxiety, anhedonia and deficiency of learning and memory [3] and to be a risk factor for psychosomatic or psychiatric illness, such as anxiety $[4,5]$. Furthermore, stress is associated with oxidative damage (i.e. free radical damage) [6]. The central nervous system is more vulnerable to free radical damage that induce brain's high oxygen consumption, relative paucity of antioxidant enzymes and also abundant lipid content [7]. Acute restraint stress stimulates numerous cellular cascades that lead to increased production of reactive oxygen species (ROS) [8] and nitric oxide $(\mathrm{NO})$-producing neurons regulate the response of the HPA axis to various stress models [9]. Increased 
physiological stress is also related to the overproduction of reactive oxygen metabolites, and without sufficient ability to clear those metabolites, can have direct deleterious effects on tissues and ultimately survival [10] . On the other hand, decreased activities of antioxidant enzymes dismutase and such as glutathione peroxidase (GPx) and superoxide dismutase have been reported in rodents submitted to restraint stress [11]. Recently, many studies proved the antidepressant effect of compounds or materials possessing antioxidant-like properties and they may be of interest as a therapeutic agent for the treatment of depressive disorders [12-15].

Human placenta hydrolysate (hPH) is known to consist of amino acids, nucleic acids, minerals and unknown effective materials [16, 17]. hPH was used for wound healing or immune enhancement where it exerted its therapeutic activities via the regulation of $\mathrm{NO}$ production [18-20]. hPH was usually used for treatment of various diseases such as chronic liver diseases, menopausal syndrome, chronic fatigue, and skin pigment disease [21]. In addition, human placental extract ameliorates structural lung changes [22] and protect cartilage degradation [23] and has anti-inflammatory and analgesic effect [24] and pain relief [25] in animal test. Tohoku et al. reported that subchronic administration of placental extract had the effect of increasing all the monoamines and decreasing the monoamine oxidase (MAO) activity [26]. Also, placental extract improves hippocampal neuronal loss and fear memory impairment resulting from chronic restraint stress in ovariectomized mice [27]. Moon et al. also reported anti-fatigue effect of porcine placenta on mice [28]. Another study showed that human placental extract are associated with elevated maternal pain threshold to noxious stimuli [25]. However, its mechanisms of stress-induced depression in animal model remain unknown. In the present study, we focused on the biological effects of hPH on stress induced depressive rats.

However, animal model studies on $\mathrm{hPH}$ are insufficient to scientifically demonstrate its working mechanisms.

In this study, we aimed to investigate whether $\mathrm{hPH}$ could modulate depressive-like behavior and production of oxidative stress markers. To achieve this goal, hPH's antidepressant effect was tested via an elevated plus maze (EPM) and forced swimming test (FST). Moreover, the influence of hPH on the levels of NADPH-d and GPx was further assessed in the brain regions using the enzyme linked immunosorbent assay (ELISA) and immunohistochemistry (IHC).

\section{Methods}

\section{Animals}

Male Sprague-Dawley (SD) rats weighing 250-280 g were purchased from Samtako Inc. (Osan, Korea). The animals were acclimated for at least 1 week prior to the experimentation. They were housed in individual cages under 12/12-h light/dark cycle and at room temperature. Food and water were made available ad libitum. Experiments were approved by the Kyung Hee University Institutional Animal Care and Use Committee (KHUASP (SE)-13-014) and the experimental protocol was also approved by the Institutional Review Committee for the use of Human or Animal Subjects.

\section{Preparation of hPH}

Human placenta hydrolysate $(\mathrm{hPH})$ is prepared with human placenta (including umbilical cord). The placenta is acquired free of charge at the obstetrics and gynecology which is contracted with Green Cross WellBeing in Korea, along with a consent from donation from donor. The hydrolysate of human placenta is manufactured by chemical process with $\mathrm{HCl}$ and pepsin, followed by dialysis, heat treatment and hydrolysis. hPH consists of various amino acids including leucine $(0.12 \%)$, arginine $(0.08 \%)$, alanine $(0.08 \%)$, phenylalanine $(0.08 \%)$, serine $(0.07 \%)$, threonine $(0.06 \%)$, valine $(0.04 \%)$, tyrosine $(0$. $03 \%)$, methionine $(0.03 \%)$, lysine $(0.1 \%)$. Insoluble macromolecules, such as polysaccharides, polynucleotides, etc. were excluded during the manufacturing process.

\section{Stress procedures}

SD male rats were exposed to repeated immobilization stress (4 h/day for 7 days).

hPH used in this study (Laennec, Green Cross WellBeing) was manufactured by Green Cross Corp. through the hydrolysis of human placenta with $\mathrm{HCl}$ and pepsin. $\mathrm{hPH}(0.02 \mathrm{ml}, 0.2 \mathrm{ml}$ or $1 \mathrm{ml} / \mathrm{rat})$ was injected intravenously $30 \mathrm{~min}$ before the daily stress session in $\mathrm{hPH}$ groups, while control groups were given sterile saline. Rats were randomly divided into five groups: the naïve normal group (normal, $N=10$ ), the stressed and saline treated group (control, $N=6$ ), the stressed and hPH 0 . $02 \mathrm{ml}$ treated group (hPH 0.02, N=7), the stressed and $\mathrm{hPH} 0.2 \mathrm{ml}$ treated group (hPH $0.2, N=8)$ and, the stressed and hPH $1 \mathrm{ml}$ treated group $(\mathrm{hPH} 1, \mathrm{~N}=6)$. As a positive control for the purpose of comparison, fluoxetine was dissolved in saline and administered orally (30 mg/kg) daily for 1 week.

\section{Forced swimming test (FST)}

FST is usually used tests for assessing antidepressant activity. The transparent Plexiglas cylinder $(50 \mathrm{~cm}$ deep, $20 \mathrm{~cm}$ diameter) filled with $26{ }^{\circ} \mathrm{C}$ water to a depth of $30 \mathrm{~cm}$ at room temperature. The rats were tested in the cylinder for $15 \mathrm{~min}, 24 \mathrm{~h}$ prior to the 5 -min swimming test. The following behaviors were recorded by trained two observers. Climbing behavior was defined as vertical motion of the forepaws along the side of the wall. 
Swimming behavior was defined as movement throughout the swim cylinder. Immobility time was defined when the rat made no further attempts to move four paws [29].

\section{Elevated plus maze (EPM)}

After exposure to stress, animals were immediately subjected to EPM tests. The apparatus used in the present study consisted of two closed arms $(50 \times 10 \times 40 \mathrm{~cm}$ each), two open arms $(50 \times 10 \mathrm{~cm}$ each $)$, and a central platform $(10 \times 10 \mathrm{~cm})$, arranged such that the open arms and closed arms were directly opposite each other. The EPM apparatus was constructed from black Plexiglas. Animals were placed in the center and then the parameters were recorded during the 5-min. The time spent on the open arms and the closed arms of the maze was video-taped and recorded for $5 \mathrm{~min}$ by S-MART program (Pan-Lab, Barcelona, Spain).

\section{Anesthetic and euthanasia}

After the behavioral tests, rats were anesthetized with sodium pentobarbital $(80 \mathrm{mg} / \mathrm{kg})$ intraperitoneally.

\section{Glutathione peroxidase (GPx) measurement}

(ELISA development system, TX, USA). Brain tissue protein was extracted using by PRO-PREP ${ }^{\mathrm{Tm}}$ solution. The tissue samples were centrifuged at $20,000 \times$ g for $10 \mathrm{~min}$ at $4 \cdot \mathrm{C}$. The supernatant was transferred to another tube and was analyzed by ELISA kit Samples (200 ul) and standards were transferred to GPx antibody-coated 96 well plates and assay cocktail $(150 \mathrm{ul})$ was added into all wells. After $10 \mathrm{~min}$ incubation, the optical density at 405-414 nm was determined 6 times for 30 min using a microplate reader (Bio-Rad 680, CA, USA). Sample values were calculated from a standard curve.

\section{NADPH-d staining}

After the behavioral testing was completed, then rats were perfused $1 \mathrm{X}$ PBS perfusate containing heparin, followed by $800 \mathrm{ml}$ of $4 \%$ paraformaldehyde in $0.1 \mathrm{M}$ PBS. The brains were placed fixed brain in $20 \%$ sucrose solution and incubate at $4{ }^{\circ} \mathrm{C}$ overnight. The brains were cut through the midline with a fresh blade at the level of the PVN. Brain tissue were incubated for $30 \mathrm{~min}$ in 0 .

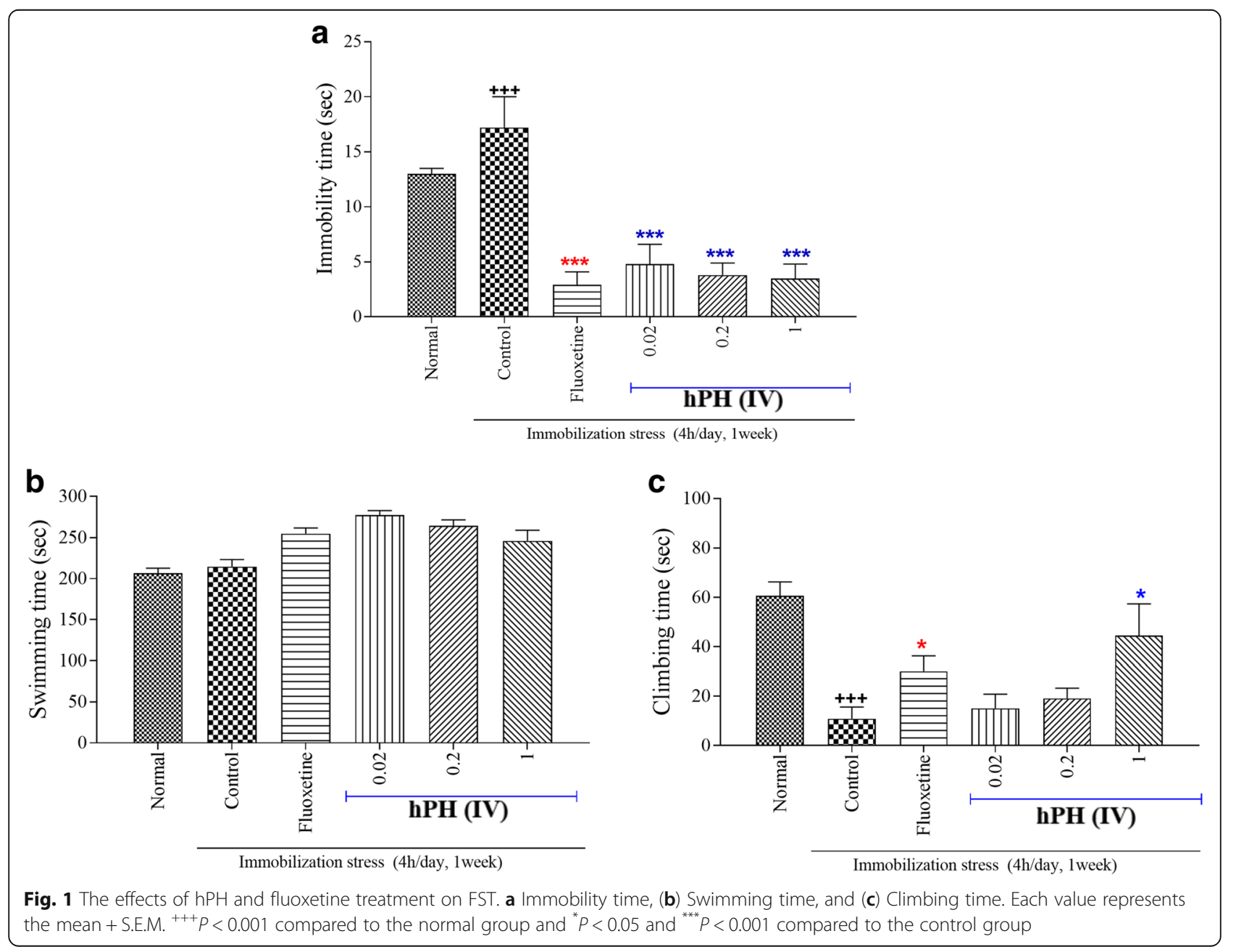


$1 \mathrm{mg} / \mathrm{ml}$ nitroblue tetrazolium (Sigma, MO, USA) and 0. $1 \mathrm{mg} / \mathrm{ml} \beta$-nicotinamide adenine dinucleotide phosphate (NADPH) (Sigma, MO, USA) in $0.05 \mathrm{M} \mathrm{PBST}$ at $37^{\circ} \mathrm{C}$. And then, the sections were rinsed three times $(10 \mathrm{~min}$ each) in 0.05 M PBS. The slides were air-dried and then coverslipped with Permount ${ }^{\text {tax }}$ solution (Fisher Scientific, CA, USA). The number of NADPH-d positive cells were measured from areas of $200 \mathrm{um}^{2}$ according to the atlas of Paxinos and Watson [30] under the light microscope (DP-20, Olympus, CA, USA).

\section{Data analysis}

All the results are expressed as mean and standard error (SEM). One-way analysis of variance (ANOVA) was performed using SPSS 15.0 software (SPSS Inc., IL, USA) followed by the post hoc least significant difference (LSD) test. An unpaired t-test was performed to determine statistical significance for fluoxetine versus saline comparison. $P$ values $<0.05$ were considered statistically significant.

\section{Results}

\section{Forced swimming test}

In the forced-swimming test (FST), rats were tested to avoid negative situation (learned helplessness, Fig. 1a-c). Animals displaying increased helplessness, which is a sign of depressive-like behavior. In the FST, the control groups showed longer immobility time than the normal group (Fig. 1a, p < 0.001). However, the immobility time was significantly decreased in $\mathrm{hPH}$ treated groups, compared to the control group (Fig. 1a, p <0.001). The swimming time was not significant difference among groups (Fig. 1b). In addition, the active behavior (climbing) was increased in the hPH $1 \mathrm{ml}$ treated group compared to the control group (Fig. 1c, p < 0.05).

\section{Elevated plus maze}

As shown in Fig. 2, the one-way ANOVA revealed a significant difference between groups regarding the time spent in the open arms or close arms. The control group significantly decreased the time spent in the open arms and increased time in the closed arms compared to that of the normal group. Fluoxetine treatment showed a significantly longer period of time spent in the open arms than that of the control group $(p<0.01)$. Although it was not significant, treatment with $\mathrm{hPH}$ also produced a decreasing trend in anxiety behavior on the EPM.

\section{Glutathione peroxidase (GPx) measurement}

GPx levels in the cortex, hypothalamus and hippocampus were changed after repeated stress (Fig. 3). hPH or fluoxetine treated group showed a trend of higher GPx levels in the hippocampus when compared to the control group. In contrast, GPx levels within the cortex and hypothalamus were not affected by the treatment of $\mathrm{hPH}$.

\section{NADPH-d staining}

The results of the number of the NADPH-d-positive neurons are shown in Fig. 4a-g. The expression of $\mathrm{NADPH}$-d-positive neurons in the paraventricular nucleus (PVN) of the control group was significantly increased by the repeated immobilization stress, as compared to that of the normal group $(p<0.001)$. However, the expression of NADPH-d-positive neurons in the $\mathrm{hPH}$ treated group was significantly lower than that of the control group $(p<0.01)$.

\section{Discussion}

This study proved that the treatment with hPH produced significant decreases in the despair behavior in the FST compared to the control group. The hPH treated groups showed markedly reduced expression of the NADPH-d in the PVN compared to the control
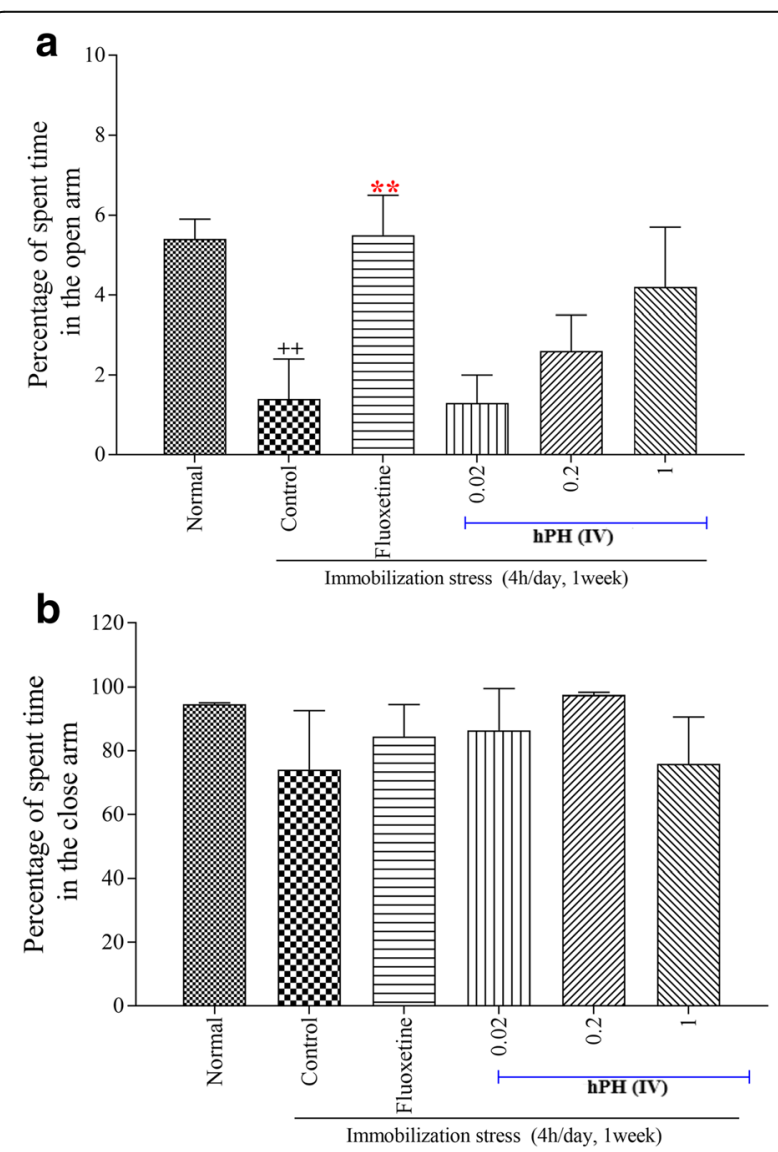

Fig. 2 The effects of hPH on EPM. a percentage of spent time in the open arm and (b) percentage of spent time in the close arm. Each value represents the mean + S.E.M. ${ }^{++} P<0.01$ compared to the normal group; ${ }^{* *} P<0.01$ compared to the control group 


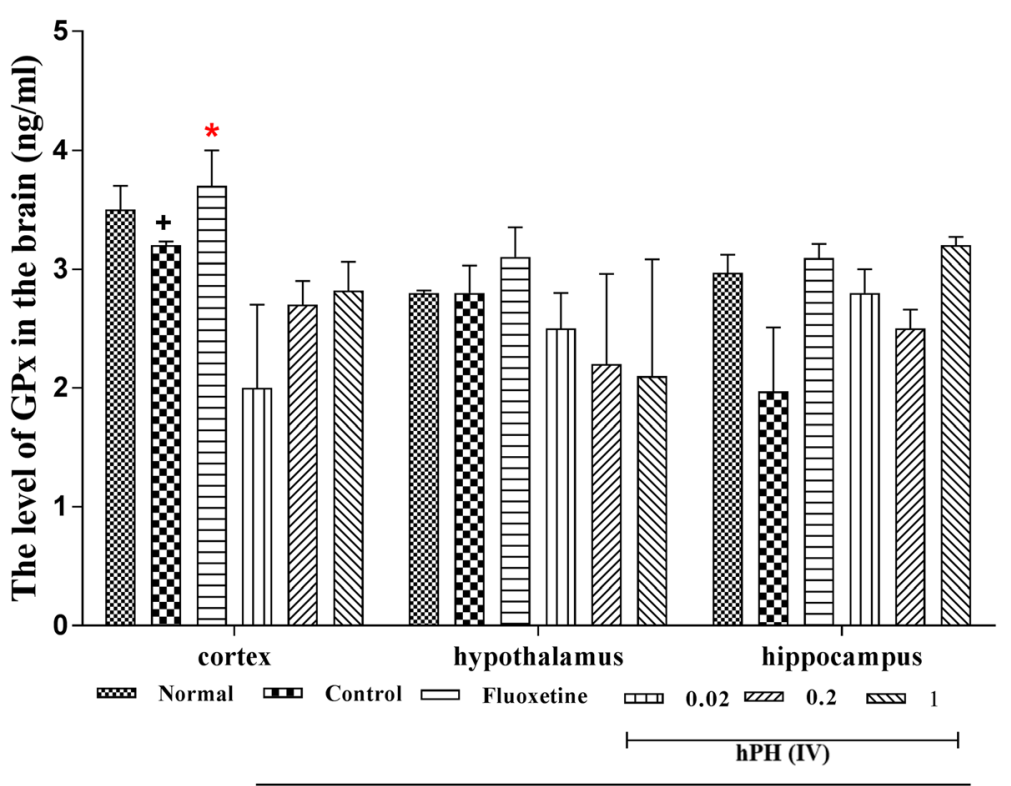

Immobilization stress $(4 \mathrm{~h} /$ day, 1 week $)$

Fig. 3 The effects of $\mathrm{hPH}$ treatment on the level of GPx in the brain. Each value represents the mean + S.E.M. ${ }^{+} P<0.05$ compared to the normal group; ${ }^{*} P<0.05$ compared to the control group

group. In addition, the repeated treatment of hPH showed an increasing trend of GPx levels in the hippocampus when compared to the control group. These results suggested that the effects of the repeated treatment of $\mathrm{hPH}$ are mediated by the regulation of a repeated stress-induced depressive behavior and the oxidative stress system in the brain.

In a pilot study, we compared the effects of various routes of administration on the immobility in FST using intravenous, intramuscular or subcutaneous injections of $\mathrm{hPH}(0.002,0.02,0.2,1$ and $2 \mathrm{ml} / \mathrm{rat})$. It was found that the most effective route to reduce immobility was intravenous injection with ranges of 0.2 to $2 \mathrm{ml}$ (data not shown). Therefore, we used intravenous injections of $\mathrm{hPH}$ at the doses of $0.02,0.2$ and $1 \mathrm{~mL} /$ rat in this study.

Chronic stress induces oxidative stress via hyperactivation of the hypothalamic pituitary adrenal (HPA) axis, leading to oversecretion of corticosterone [31]. Moreover, the oversecretion of corticosterone induces depressive-like behaviors such as anxiety and despair. The present study showed that the repeated immobilization stress increased the despair behavior in the FST which was reduced by treatment with $\mathrm{hPH}$ or fluoxetine. Recently, some studies reported that repeated restraint stress induced not only depressive behavior but also oxidative stress in the brain region [32-37]. The brain is more susceptible to oxidative stress due to its relatively high consumption of oxygen, high iron content, high fatty acid peroxidation, and low antioxidant capacity compared to other organs [32-34, 36]. Nitric oxide $(\mathrm{NO})$ is the major oxidative stress marker for cellular component's damage $[35,37-40]$ and repeated stress increases the NO levels in the brain [9, 41, 42]. Our result also showed that repeatedly stressed rats have significantly increased levels of NADPH-d expression in the PVN. NADPH oxidase has been studied as a major source of reactive oxygen species (ROS) generation in mammalian cells. Sanchez et al. reported that the swim stress enhances the NADPH-d histochemical staining in the PVN of the hypothalamus [43]. In mice, the repeated stress mediates depressive behavior through the upregulation of NADPH oxidase and the resultant metabolic oxidative stress, and the treatment of NADPH oxidase inhibitor apocynin during the stress or post-stress period reduced stress induced responses [8]. In the present study, hPH decreased the expression of NADPH-d in the PVN, suggesting that the inhibition of NADPH oxidase may provide beneficial anti-stress effects. Among important changes in the brain of stress-induced animal models, accumulation of oxidative stress has been noted [8, 44-46]. GPx, an antioxidant enzyme, is a defense system against oxidative stress [47-49], and many antioxidants and free radical scavenging enzyme systems exist in the cell to protect it against the damaging effects of free radicals produced as a part of normal cell respiration and other cellular processes [50]. However, repeated stress affected the level of the antioxidant components as superoxide dismutase, GPx, catalase in 

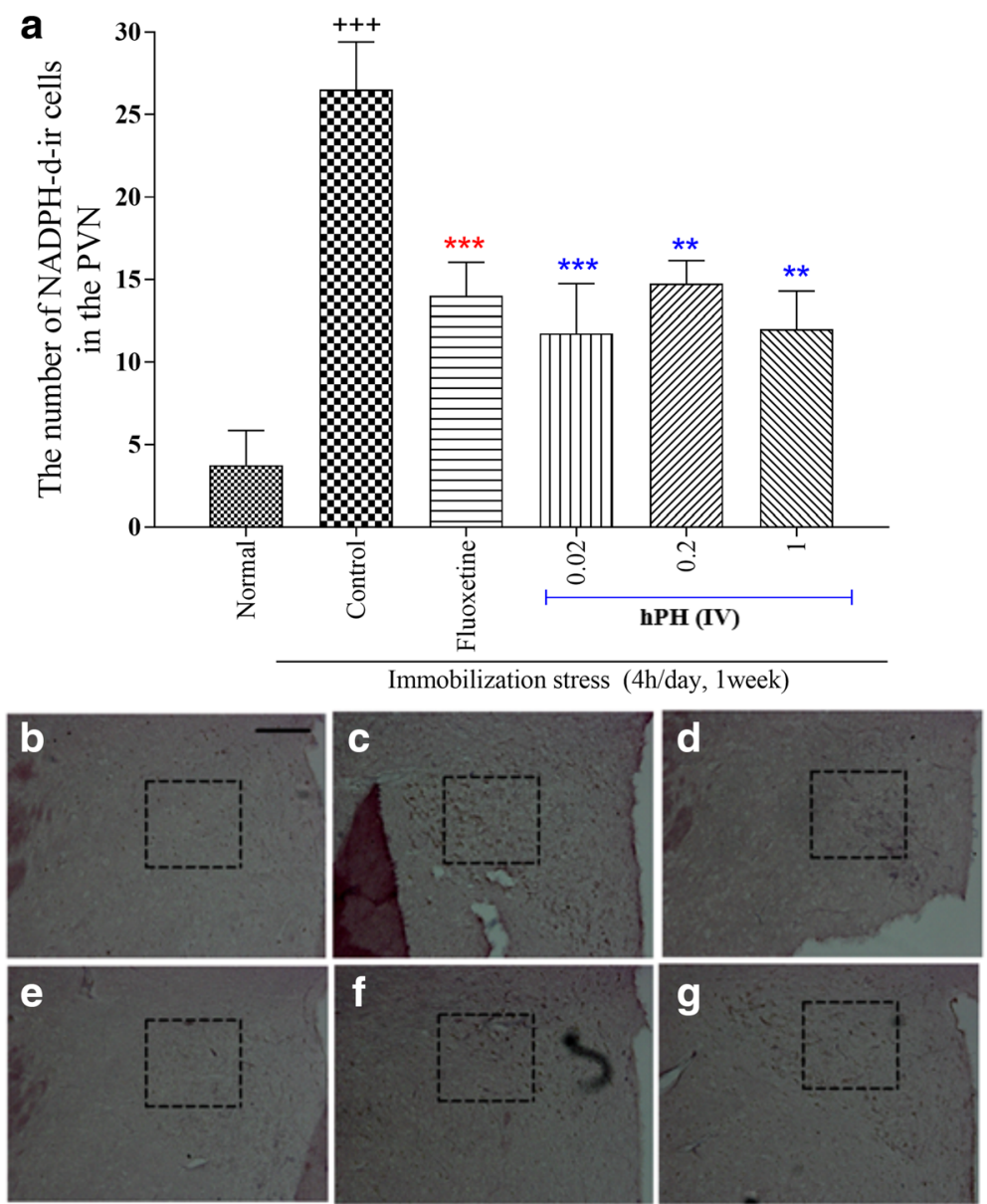

Fig. 4 a The effects of hPH and fluoxetine treatment on the expression of NADPH-d immunoreactive neurons in the PVN of the each treated group. $\mathbf{b}$ - $\mathbf{g}$ Immunohistochemical staining of NADPH-d in the PVN obtained from the each treatment group. b Normal, (c) Control, (d) Fluoxetine, (e) hPH 0.02, (f) hPH 0.2, and (g) hPH 1, respectively. Each value represents the mean + S.E.M. ${ }^{+++} P<0.001$ compared to the normal group and ${ }^{* *} P<0.01,{ }^{* * *} P<0.001$ compared to the control group

the central and peripheral nervous systems [51-54]. Consistent with previous studies, our results showed that the repeatedly stressed rats showed a decreasing trend of GPx levels in the brain regions. Moreover, the repeated treatment of hPH or fluoxetine showed a trend toward increased GPx levels in the hippocampus of the repeatedly stressed rats. Other studies also reported that fluoxetine, one of antidepressants, reduced the amounts of free oxygen radicals [55], catalase levels, and lipid peroxidation [56]. Some studies showed that the human placenta extract and their components have neuro-protective effects by regulating antioxidant actions [57-60].

Taken together, repeated treatment of hPH has an antioxidant effect and HPA axis modulatory activity that could be the important therapeutic strategy for repeated stress-induced behavioral and biochemical changes. These results suggest that hPH may play an active role in the treatment of stress-related responses via regulation of oxidative stress.

\section{Conclusions}

This study demonstrated that hPH has anti-stress effects via the regulation of nitric oxide (NO) synthase and antioxidant activity in the brain. These results suggest that $\mathrm{hPH}$ may be useful in the treatment of stress-related diseases such as chronic fatigue syndrome.

\section{Funding}

This research was supported by the National Research Foundation of Korea (NRF) grant funded by the Korean government (NRF-2013S1A2A1A01064496 and NRF-2016M3C7A1905384) and sponsored by Green Cross Corp. and Green Cross WellBeing.

Availability of data and materials

Data supporting our findings are contained within the manuscript.

Authors' contributions

HJP, HSS and SYL conducted the animal experiment and analyzed the data. ISS, HJP, HSS, DHH, HJL, CTO, HJH and HJJ participated in design of the study and preparation of the manuscript. All authors read and approved the final manuscript. 


\section{Ethics approval and consent to participate}

All the experiments were approved by the Kyung Hee University Institutional Animal Care and Use Committee (KHUASP (SE)-13-014) and the experimental protocol was also approved by the Institutional Review Committee for the use of Human or Animal Subjects. hPH used in this study (Laennec, Green Cross WellBeing) was manufactured by Green Cross Corp.

\section{Consent for publication}

\section{Not applicable.}

\section{Competing interests}

As a Section Editor of the Journal, I declare that I have no competing interests. The authors declare that they do not have any conflict of interest in the publication of this article. All authors read the manuscript and approved the final version.

\section{Publisher's Note}

Springer Nature remains neutral with regard to jurisdictional claims in published maps and institutional affiliations.

\section{Author details}

'Department of Science in Korean Medicine, Graduate School, College of Korean Medicine, Kyung Hee University, Seoul 02447, South Korea. ${ }^{2}$ Business Development Division, Green Cross WellBeing, Seongnam, Gyeonggi-Do 13595, South Korea. ${ }^{3}$ Corporate Development Division, Green Cross Corp, Yongin, Gyeonggi-Do 16924, South Korea. ${ }^{4}$ Department of Physiology, College of Medicine, Kyung Hee University, Seoul, South Korea. ${ }^{5}$ Department of Food Science \& Biotechnology, College of Science and Engineering, Kyonggi University, Suwon, South Korea.

\section{Received: 12 June 2017 Accepted: 29 March 2018}

\section{Published online: 08 May 2018}

\section{References}

1. Park HJ, Shim HS, Kim H, Kim KS, Lee H, Hahm DH, Shim I. Effects of Glycyrrhizae Radix on repeated restraint stress-induced neurochemical and behavioral responses. Korean J Physiol Pharmacol. 2010;14(6):371-6.

2. Pare WP. The effect of chronic environmental stress on stomach ulceration, adrenal function, and CONSUMMATORY behavior in the rat. Aust J Psychol. 1964;57:143-51.

3. Sidebottom AC, Hellerstedt WL, Harrison PA, Hennrikus D. An examination of prenatal and postpartum depressive symptoms among women served by urban community health centers. Arch Womens Ment Health. 2014;17(1): 27-40.

4. Iwata M, Ota KT, Duman RS. The inflammasome: pathways linking psychological stress, depression, and systemic illnesses. Brain Behav Immun. 2013;31:105-14.

5. Petrowski K, Wintermann GB, Siepmann M. Cortisol response to repeated psychosocial stress. Appl Psychophysiol Biofeedback. 2012;37(2):103-7.

6. Park HJ, Shim HS, Chung SY, Lee TH, Shim I. Soyo-san reduces depressivelike behavior and proinflammatory cytokines in ovariectomized female rats. BMC Complement Altern Med. 2014;14:34.

7. Patil R, Dhawale K, Gound H, Gadakh R. Protective effect of leaves of Murraya koenigii on reserpine-induced Orofacial dyskinesia. Iran J Pharm Res. 2012;11(2):635-41.

8. Seo JS, Park JY, Choi J, Kim TK, Shin JH, Lee JK, Han PL. NADPH oxidase mediates depressive behavior induced by chronic stress in mice. J neurosci. 2012;32(28):9690-9.

9. Dzambazova EB, Landzhov BV, Bocheva Al, Bozhilova-Pastirova AA. Effects of D-kyotorphin on nociception and NADPH-d neurons in rat's periaqueductal gray after immobilization stress. Amino Acids. 2011:41(4):937-44.

10. Lucas LD, French SS. Stress-induced tradeoffs in a free-living lizard across a variable landscape: consequences for individuals and populations. PLOS One. 2012;7(11):e49895.

11. Toma VA, Farcas AD, Parvu M, Silaghi-Dumitrescu R, Roman I. CA3 hippocampal field: cellular changes and its relation with blood nitrooxidative stress reveal a balancing function of CA3 area in rats exposed to repetead restraint stress. Brain Res Bull. 2016;130:10-7.

12. Lenzi J, Rodrigues AF, Ros AS, de Castro BB, de Lima DD, Magro DD, Zeni AL: Ferulic acid chronic treatment exerts antidepressant-like effect: role of antioxidant defense system. Metab Brain Dis 2015.
13. Sacchet C, Mocelin R, Sachett A, Bevilaqua F, Chitolina R, Kuhn F, Boligon AA, Athayde ML, Roman Junior WA, Rosemberg DB, et al. Antidepressantlike and antioxidant effects of Plinia trunciflora in mice. Evidence-based complementary and alternative medicine : eCAM. 2015;2015:601503.

14. Silva MC, de Sousa CN, Gomes PX, de Oliveira GV, Araujo FY, Ximenes NC, da Silva JC, Silva Vasconcelos G, Leal LK, Macedo D, et al. Evidence for protective effect of lipoic acid and desvenlafaxine on oxidative stress in a model depression in mice. Prog Neuro-Psychopharmacol Biol Psychiatry. 2016;64:142-8.

15. Yu HC, Wu J, Zhang HX, Zhang HS, Qiao TT, Zhang JX, Zhang GL, Sui J, Li LW, Zhang LR et al: Antidepressant-like and anti-oxidative efficacy of Campsis grandiflora flower. J Pharm Pharmacol 2015.

16. Hong JW, Lee WJ, Hahn SB, Kim BJ, Lew DH. The effect of human placenta extract in a wound healing model. Ann Plast Surg. 2010;65(1):96-100.

17. Jung J, Lee HJ, Lee JM, Na KH, Hwang SG, Kim GJ. Placenta extract promote liver regeneration in CCl4-injured liver rat model. Int Immunopharmacol. 2011:11(8):976-84.

18. Chakraborty D, Basu JM, Sen P, Sundar S, Roy S. Human placental extract offers protection against experimental visceral leishmaniasis: a pilot study for a phase-I clinical trial. Ann Trop Med Parasitol. 2008;102(1):21-38.

19. Chandanwale A, Langade D, Mohod V, Sinha S, Ramteke A, Bakhshi GD, Motwani M. Comparative evaluation of human placental extract for its healing potential in surgical wounds after orthopaedic surgery: an open, randomised, comparative study. J Indian Med Assoc. 2008;106(6):405-8.

20. Kaushal V, Verma K, Manocha S, Hooda HS, Das BP. Clinical evaluation of human placental extract (placentrex) in radiation-induced oral mucositis. Int J Tissue React. 2001;23(3):105-10.

21. Kong MH, Lee EJ, Lee SY, Cho SJ, Hong YS, Park SB. Effect of human placental extract on menopausal symptoms, fatigue, and risk factors for cardiovascular disease in middle-aged Korean women. Menopause. 2008; 15(2):296-303

22. Samiei F, Jamshidzadeh A, Noorafshan A, Ghaderi A. Human placental extract ameliorates structural lung changes linduced by Amiodarone in rats. Iran J Pharm Res. 2016:15(Suppl):75-82.

23. Kim JK, Kim TH, Park SW, Kim HY, Kim S, Lee S, Lee SM. Protective effects of human placenta extract on cartilage degradation in experimental osteoarthritis. Biol Pharm Bull. 2010;33(6):1004-10.

24. Lee KH, Kim TH, Lee WC, Kim SH, Lee SY, Lee SM. Anti-inflammatory and analgesic effects of human placenta extract. Nat Prod Res. 2011;25(11):1090-100.

25. Gurgel LA, Santos FA, Rao VS. Effects of human placental extract on chemical and thermal nociception in mice. Eur J Pain. 2000;4(4):403-8.

26. Banerjee KK, Bishayee A, Chatterjee M. Effects of human placental extract on brain monoamines and monoamine oxidase activity in rats. Tohoku J Exp Med. 1995;176(1):17-24.

27. Takuma K, Mizoguchi H, Funatsu Y, Kitahara Y, Ibi D, Kamei H, Matsuda T, Koike K, Inoue M, Nagai T, et al. Placental extract improves hippocampal neuronal loss and fear memory impairment resulting from chronic restraint stress in ovariectomized mice. J Pharmacol Sci. 2012;120(2):89-97.

28. Moon PD, Kim KY, Rew KH, Kim HM, Jeong HJ. Anti-fatigue effects of porcine placenta and its amino acids in a behavioral test on mice. Can J Physiol Pharmacol. 2014:92(11):937-44.

29. Castagne V, Moser P, Roux S, Porsolt RD, et al. Curr Protoc Neurosci. 2011; Chapter 8:Unit 8 10A.

30. Paxinos G, Watson C, Pennisi M, Topple A. Bregma, lambda and the interaural midpoint in stereotaxic surgery with rats of different sex, strain and weight. J Neurosci Methods. 1985;13(2):139-43.

31. Ai Z, Cheng AF, Yu YT, Yu LJ, Jin W. Antidepressant-like behavioral, anatomical, and biochemical effects of petroleum ether extract from Maca (Lepidium meyenii) in mice exposed to chronic unpredictable mild stress. J Med Food. 2014:17(5):535-42

32. Li Y, Gorelik G, Strickland FM, Richardson BC: Oxidative stress, T cell DNA methylation and lupus. Arthritis \& rheumatology (Hoboken, NJ) 2014

33. Walczak-Jedrzejowska R, Wolski JK, Slowikowska- J. The role of oxidative stress and antioxidants in male fertility. Central European journal of urology. 2013;66(1):60-7

34. Fortunato RS, Ferreira AC, Hecht F, Dupuy C, Carvalho DP: Sexual dimorphism and thyroid dysfunction: a matter of oxidative stress? J Endocrinol 2014.

35. Allain AV, Hoang VT, Lasker GF, Pankey EA, Murthy SN, Kadowitz PJ. Role of nitric oxide in developmental biology in plants, bacteria, and man. Current topics in pharmacology. 2011;15(2):25-33. 
36. Bolognin S, Cozzi B, Zambenedetti P, Zatta P: Metallothioneins and the central nervous system: from a deregulation in neurodegenerative diseases to the development of new therapeutic approaches. Journal of Alzheimer's disease : JAD 2014

37. Sun GY, Chuang DY, Zong Y, Jiang J, Lee JC, Gu Z, Simonyi A: Role of cytosolic phospholipase a in oxidative and inflammatory signaling pathways in different cell types in the central nervous system. Mol Neurobiol 2014

38. Raptis V, Georgianos PI, Sarafdis PA, Sioulis A, Makedou K, Makedou A, Grekas DM, Kapoulas S. Elevated Asymmetric Dimethylarginine is Associated With Oxidant Stress Aggravation in Patients With Early Stage Autosomal Dominant Polycystic Kidney Disease. Kidney \& blood pressure research. 2014;38(1):72-82.

39. Vitetta $L$, Linnane AW: Endocellular regulation by free radicals and hydrogen peroxide: key determinants of the inflammatory response. Inflammopharmacology 2014.

40. Wang Y, Dong J, Liu P, Lau CW, Gao Z, Zhou D, Tang J, Ng CF, Huang Y Ginsenoside Rb3 attenuates oxidative stress and preserves endothelial function in hypertension. Br J Pharmacol 2014.

41. Bajic D, Berde CB, Commons KG. Periaqueductal gray neuroplasticity following chronic morphine varies with age: role of oxidative stress. Neuroscience. 2012:226:165-77.

42. Choi WK, Wirtshafter D, Park HJ, Lee MS, Her S, Shim I. The characteristics of supramammillary cells projecting to the hippocampus in stress response in the rat. Korean J Physiol Pharmacol. 2012;16(1):17-24.

43. Sanchez F, Moreno MN, Vacas P, Carretero J, Vazquez R. Swim stress enhances the NADPH-diaphorase histochemical staining in the paraventricular nucleus of the hypothalamus. Brain Res. 1999;828(1-2):159-62.

44. Madrigal JL, Olivenza R, Moro MA, Lizasoain I, Lorenzo P, Rodrigo J, Leza JC. Glutathione depletion, lipid peroxidation and mitochondrial dysfunction are induced by chronic stress in rat brain. Neuropsychopharmacology. 2001; 24(4):420-9

45. Sahin E, Gumuslu S. Alterations in brain antioxidant status, protein oxidation and lipid peroxidation in response to different stress models. Behav Brain Res. 2004;155(2):241-8

46. Tsiakitzis K, Kourounakis AP, Tani E, Rekka EA, Kourounakis PN. Stress and active oxygen species-effect of alpha-tocopherol on stress response. Arch Pharm. 2005;338(7):315-21.

47. Kruzel ML, Actor JK, Zimecki M, Wise J, Ploszaj P, Mirza S, Kruzel M, Hwang SA, Ba X, Boldogh I. Novel recombinant human lactoferrin: differential activation of oxidative stress related gene expression. J Biotechnol. 2013; 168(4):666-75

48. Lu J, Holmgren A. The thioredoxin antioxidant system. Free Radic Biol Med. 2014;66:75-87.

49. Parvin S, Lee OR, Sathiyaraj G, Khorolragchaa A, Kim YJ, Yang DC. Spermidine alleviates the growth of saline-stressed ginseng seedlings through antioxidative defense system. Gene. 2014;537(1):70-8.

50. Zaidi SM, Al-Qirim TM, Hoda N, Banu N. Modulation of restraint stress induced oxidative changes in rats by antioxidant vitamins. J Nutr Biochem. 2003;14(11):633-6.

51. Enache M, Van Waes V, Vinner E, Lhermitte M, Maccari S, Darnaudery M. Impact of an acute exposure to ethanol on the oxidative stress status in the hippocampus of prenatal restraint stress adolescent male rats. Brain Res. 2008:1191:55-62.

52. Noschang CG, Krolow R, Pettenuzzo LF, Avila MC, Fachin A, Arcego D, von Pozzer Toigo E, Crema LM, Diehl LA, Vendite D, et al. Interactions between chronic stress and chronic consumption of caffeine on the enzymatic antioxidant system. Neurochem Res. 2009;34(9):1568-74.

53. Sahin E, Gumuslu S, Ozturk O, Abidin I, Yargicoglu P, Agar A. Marked changes in erythrocyte antioxidants and lipid peroxidation levels of rats exposed to acute, repeated and chronic restraint stress. Pharmazie. 2004 59(12):961-4.

54. Yoo KY, Lee CH, Park JH, Hwang IK, Park OK, Kwon SH, Choi JH, Kim DJ, Kwon YG, Kim YM, et al. Antioxidant enzymes are differently changed in experimental ischemic hippocampal CA1 region following repeated restraint stress. J Neurol Sci. 2011;302(1-2):33-42

55. Young KC, Bai CH, Su HC, Tsai PJ, Pu CY, Liao CS, Lin YM, Lai HW, Chong LW, Tsai YS, et al. Fluoxetine a novel anti-hepatitis C virus agent via ROS-, JNK-, and PPARbeta/gamma-dependent pathways. Antivir Res. 2014;110: 158-67.

56. Galecki P, Szemraj J, Bienkiewicz M, Florkowski A, Galecka E. Lipid peroxidation and antioxidant protection in patients during acute depressive episodes and in remission after fluoxetine treatment. Pharmacological reports. 2009:61(3):436-47.

57. Chakraborty PD, Bhattacharyya D, Pal S, Ali N. In vitro induction of nitric oxide by mouse peritoneal macrophages treated with human placental extract. Int Immunopharmacol. 2006;6(1):100-7.

58. Park SY, Phark S, Lee M, Lim JY, Sul D. Anti-oxidative and anti-inflammatory activities of placental extracts in benzo[a]pyrene-exposed rats. Placenta. 2010;31(10):873-9.

59. Sidle EH, Casselman R, Smith GN. Effect of cigarette smoke on placental antioxidant enzyme expression. Am J Physiol Regul Integr Comp Physiol. 2007:293(2):R754-8.

60. Watanabe S, Togashi S, Takahashi N, Fukui T. L-tryptophan as an antioxidant in human placenta extract. J Nutr Sci Vitaminol. 2002;48(1):36-9.

\section{Submit your next manuscript to BioMed Central and we will help you at every step:}

- We accept pre-submission inquiries

- Our selector tool helps you to find the most relevant journal

- We provide round the clock customer support

- Convenient online submission

- Thorough peer review

- Inclusion in PubMed and all major indexing services

- Maximum visibility for your research

Submit your manuscript at www.biomedcentral.com/submit 